\title{
Effect of Organizational Capability on Firms Growth: Implications on SMEs in Anambra State, Nigeria
}

\author{
Anugwu Clara Chika, Nwosu Kanayo Chike, and Okoli Emmanuel Nuel Ifeanyi
}

\section{ABSTRACT}

\begin{abstract}
Organizational capabilities are seen as the firm context in which the organization members work in order to contribute to growth of the firm. Thus, inadequate organizational capabilities have resulted to numerous problems for many Small and Medium Enterprises (SMEs) with growing difficulties in their ability to perform and attain sustainable growth. Numerous researches relating to organizational capabilities and firm's growth have been conducted in the literature but none of these have examined the implications of organizational capability on firm's growth. This research therefore examined the implications of organizational capability on firm's growth, its implications of SMEs in Anambra State. The research employed a descriptive research design. The study population was one hundred and fifty-two business owners and managers of selected SMEs in Anambra State. Complete enumeration was used. Primary data was used and was collected using questionnaires. The questionnaire was validated using face and content validity. Reliability of the instrument was done with Cronbach Alpha indicates high internal consistency. Data collected was analyzed using correlation analysis. Findings from the study indicated that research and development capability have no significant positive relationship on firm's growth, while human resource capability has a significant positive relationship on firm's growth. The study concluded that organizational capabilities are key success factor for driving firm's growth among SMEs in Anambra State, Nigeria. The study recommended that for SMEs to achieve sustainable growth, business owners and managers should increase their degree of firm's interaction with the environment and add more value to human resources capability.
\end{abstract}

Keywords: Firm's Growth, Human resource capability, Organizational Capability, Research and development capability, SMEs.

\section{INTRODUCTION}

The fundamental question in entrepreneurship is how firms attain growth and maintain a competitive advantage. Organizational capabilities have important implications for business performance for gaining a sustainable competitive advantage. The market-driven business sector has developed a high level of six key marketing capabilities (in market research, pricing, product development, channel, market promotion and market management) compared to their less rival business units' market-driven in the four enterprise performance metrics, viz. growth, value, customer satisfaction and flexibility [1].

Firms with high adaptability probably have better performance than low adapters, despite the high cost and inefficiency [2]. Moore \& Fairhurst [3] opined that short-term product life in the retail business presents a number of challenges for the retail industry. To survive in this industry, it is important that the participant develops and maintains the necessary business capabilities. In other words, the most unique feature of market-oriented firms is their management of market capability and customer relationship.
Submitted : August 10, 2021

Published : September 02, 2021

ISSN: $2507-1076$

DOI: $10.24018 /$ ejbmr.2021.6.5.1050

Anugwu Clara Chika

Dept. of Entrepreneurship Studies, Nnamdi Azikiwe University, Awka Nigeria.

(e-mail: cc.anugwu unizik.edu.ng)

Nwosu Kanayo Chike

Nnamdi Azikiwe University, Awka, Nigeria.

(e-mail: kaykaydpommy@yahoo.com)

Okoli Emmanuel Nuel Ifeanyi*

Dept. of Entrepreneurship Studies,

Nnamdi Azikiwe University, Awka, Nigeria.

(e-mail: ie.okoli@unizik.edu.ng)

*Corresponding Author
Therefore, organizational capabilities are the ability of firms to manage its resources efficiently; it is very much involved in the planning process and effectively implementing the strategic decision-making process to attain the required results [4]. The development of organization capabilities is to help firms manage environmental turbulence and tends to improve firm growth. Vorhies \& Morgan [5] argued that a strong firm cannot consider having growth without first seeing its survival and sustainability in the market. Thus, for growth to occur, firms must survive its crises as an organization. To support this argument, Teece's [6] study emphasized that the primary importance of organizational capabilities is for the sustainability and growth of the firm. Weerawardena [7] posits that developing capabilities will help firms to sustain its business and attain higher performance.

Organizational capabilities besides being a source of new wealth for a firm provide stable tools for the firm's planners. These capabilities allow for the initiation and transformation of economic systems with robust regulation. Thus, Lopez, [8] asserted that dynamic capabilities are key to success in promoting the strategic planning of the future of the firm. As 
managers become more in charge for making their own decisions, a clear understanding of the power and usefulness of the firm is needed in order to attain organizational growth and competitive advantage [9].

Innovative core assets (research and development, manufacturing, and marketing) alone cannot lead to sustainable growth. Instead, complementary innovation assets (learning, research, organizational resource allocation and strategy planning) not only bring the company's technology into any powerhouse, but also help the firm make sustainable competitive advantage. In this vein, the purpose of this study is to investigate effect of organizational capabilities on firms' growth among selected SMEs in Anambra State Nigeria.

\section{A. Statement of the Problem}

As global industries expand, new opportunities exist for less developed countries to adapt their firms to global profitability. Nigeria is undoubtedly among the countries that have not made the most of the window of opportunity of globalization. This is often a problem where the business environment in which it operates creates a number of challenges that prevent managers. The success or failure of any business depends on the knowledge and understanding around the business. This is because no manager can set up a successful business plan regardless of economic, political, social, and technological factors.

Managers now face challenges in businesses which require firms to build new capabilities owing to globalization. There are growing concern now about the processes and the technology as well as increasing power and customer satisfaction. Managers also face the problems of ensuring that they take advantage of what information technology has to offer and make it an integral productive part of their work environment. When a manager could not comprehend his role, could not assign duties, even when he knows, has the authority to perform the task, poses a challenge to his firm and will confront difficulties to motivate employees to give all their energy and efforts to increase productivity. Paucity of technical, human and conceptual skills arising from the background of the manager constitutes another major problem of managers and owners of SMEs in Anambra State. A manager without these skills finds it difficult to come up with new ideas, think critically and explain and apply nonexistent ideas to strengthen growth of firms. These can be noted that these are some of the problems inherent in this research.

\section{B. Objectives of the Study}

The major objective of this study is to examine the effect of organizational capabilities on firms' growth among selected SMEs in Anambra State, Nigeria. However, the study specifically:

1)Examine the effect of research and development capability on firm's growth of selected SMEs in Anambra State Nigeria.

2)Assess the effect of human resource capability on firm's growth of selected SMEs in Anambra State Nigeria.

\section{REVIEW OF RELATED LITERATURE}

\section{A. Organizational Capabilities}

The capabilities of the organization have been defined in a number of ways. The capabilities of the organization employ three different capabilities that include motivation to take a particular action, ability to take action and any understanding of the competitive environment throughout the organization [10]. From the review of the literature on capabilities, research has been done in three functional areas of the firm which include operations, customer service and product development. Operational capability is the ability of the firm to provide customers with the products we can rely on and thus provide them with services provided at competitive prices. Customer service capability is the ability of the firms to understand the requirements of different markets. Product development capability is the ability to deliver quality products by focusing on innovation.

Thus, an organizational capability is simply meaning the ability to perform or achieve certain actions or results. This means the ability of business to use competitive strategy that allows it to survive and maximize the value of its operating time. They specialize in firm's assets, resources, and market position, projecting how well it will be ready to employ strategies within the future. There is no single approach or universal measure for understanding capabilities. Consistent with Smallwood \& Ulrich [11], organizational capabilities emerge when a firm delivers on the combined competencies and skills of its individuals. Organizational capabilities enable firms to show its technical know-how into results. The power of a firm to work its day-to-day business also grows, adapt, and seek competitive advantage within the market place. Thus, the concept of capability has been extended into that of dynamic capabilities [12].

If organization wants to enhance its strategy execution rate, the primary place to start out is to agree on what really constitutes organizational capabilities. Capabilities comprise the power and capacity of a corporation expressed in terms of its human resources (quality, number, skills, and experience), physical and material resources (machines, land, and buildings), financial resources (money and credit), information resources (knowledge, databases) and intellectual resources (copyrights, designs, and patents etc.). According to Gill \& Delahaye [13] organizational capability is defined as the knowledge base that supports competitive advantage through innovation and the change achieved by building balance between the skills of individuals. Kelchner [14] sees organizational capability as the firm's ability to manage resources (such as employees) effectively to benefit more than its competitors. The firm's organizational capability must specialize in the business ability to meet the needs of the customers.

In an effort to define the capabilities required to create a new investment potential, managers and business owners must ensure that capabilities flow within the framework of the firm's strategic plan. The goals, feedback and business model of the firm must be well coordinated with the idea of the capabilities of the firm. The speed at which a firm can grow is, to a large extent, determined by the pace at which it can create and process its capabilities in response to the challenges encountered in a changing market. Organizational 
capability plays a major role in the firm's strategy; hence it helps to attain competitive advantage. This can be viewed when organizations create new energies and develop existing ones; they tend to retain profits more than competition. Customer relationships will be improved which will enable the brand to continue to thrive in the market. Day [15] rightly observed that the relationship between the organization and its customers, such as organizational capability, affects sales, loyalty and reputation and business in the future.

Cognitive management with organizational capabilities perspectives are also used to determine two important capabilities namely knowledge infrastructure and information systems. The firm should utilize the existing knowledge to create new knowledge and capabilities the process termed as absorptive capacity the study revealed technology, structure, and culture as knowledge infrastructure capability dimensions under knowledge process capability the study revealed the dimensions as acquisition, conversion, application, and protection. The firm must utilize existing knowledge to create new knowledge and capabilities that the process called as absorptive capacity that the research revealed technology, structure, and culture as dimensions of knowledge infrastructure capability under knowledge process capability research revealed the dimensions as acquisition, conversion, application and protection. Both knowledge infrastructure and information systems influence organizational capabilities [15]. Knight \& Cavusgil [16] explored the linkage between organizational capabilities, knowledge \& innovation to understand its influence on the early adoption of internationalization and performance of born global firms. Sharma \& Vredenburg [17] pointed out the introduction of a unique organizational capability is the response to a well-developed environmental response system developed at this organization. Organizational environmental strategies do a great job of achieving strong competition by developing highly competitive design capabilities.

\section{B. Firm Growth}

Firm growth is a rise within the number of desirable outcomes like sales, revenue, employment output, size, etc. It is also seen as an improvement in form and substance thanks to developmental processes even as it is in natural systems, wherein internal shifts cause increase in size and changes in the properties of the study element [18]. Nelson \& Winter [19] posit that growth is evidence of an optimal mix of the resources, competencies and daily activities of the firm. Most empirical literature has a bias for sales as a measure of growth because it is a pointer to assets growth and employee growth [20]. However, human resource is the key to promoting organization; since it will emerge as a business entrepreneur helping executives build a better organization not only for today, but for tomorrow and beyond.

Numerous researchers e.g., [21], [22], have listed the determinants and barriers to firm's growth. The determinants increase growth and are classified into three broad areas, namely: individual factors that include "personality traits, need for achievement, risk-taking, position of control, selfefficacy, extraversion, motivation for growth, personal abilities and personal background"; organizational determinants include firm characteristics, firms strategies, firm-specific resources, organizational structure, and dynamic capability; the latter factors are "environmental factors" consisting of "environmental dynamics, heterogeneity, hostility, and materiality" [21].

Storey [23] detailed the factors influencing the growth of SMEs firms into: (1) entrepreneur's resources, (2) the firm and, (3) strategy. Specifically for clusters, Rosenfeld [24] argued that the economic success of business clusters depends on 3Cs - Concepts, Connections and Competencies. Concepts factors are innovation, imitation and competition, entrepreneurial energy. Connections factors include networking and networks, connections, and intermediaries; while competencies include specialized workforce, industry leaders' attitudes, talent, and tacit knowledge.

\section{Theoretical Framework}

This study is based on the resource-based theory. This theory emphasizes that the competitive advantage and high performance of an organization can be explained by exceptional ability [25]. The concept of resource-based view (RBV) as the basis for competitive advantage lies basically on the deployment of valuable or intangible resources in the hands of the firm. In order to make short-term competition sustainable, a variety of these components are required. This actually translates into valuable resources that cannot be imitated or replaced without much effort [26].

Strategy is viewed as any unique adjustment that a firm makes between its internal resources and the skills and opportunities, and threats created by its external environment. The firm's resources and capabilities are the key consideration in strategy formulation; they are the foundation on which a firm can base its identity and formulate its strategy. The key to a resource-based approach to formulating a strategy understands the relationship between resources, capabilities, and competitive advantage. This theory is of great interest to management and many texts. It describes the ability to maximize competitive advantage when the equipment is managed so that competitors are unable to measure their results, leading to competition problems. It underscores the fact that a firm maintains the value of competition due to the wealth of its unique, small, valuable, unparalleled, undisputed, and well-defined industry.

\section{Conceptual Framework}

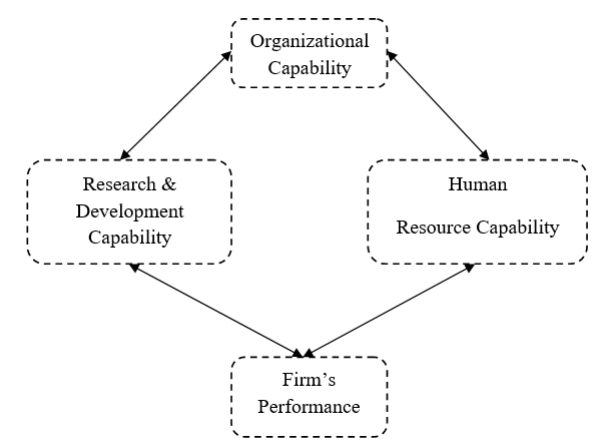

Fig. 1. Conceptualization of Organizational Capability on Firm's Growth Source: Researcher, (2021).

\section{E. Empirical Review}

Asikhia, Makinde, \& Olowoporoku [27] investigated the role of organizational capabilities in the competitiveness of selected hotels in South-west Nigeria. The study employed 
cross-sectional survey research design. The collected data were analyzed using descriptive and inferential (multiple and hierarchical regression) statistics. Findings from the study showed that organizational capabilities had significant positive effect on competitiveness of selected hotels in Southwest Nigeria. The study concluded that corporate culture, managerial knowledge, human capacity, and innovation management are key resources for driving competitiveness of hotels in Southwest Nigeria. LópezCabarcos, Oliveira-Monteiro \& Vázquez-Rodríguez [28] examined the association between organizational capabilities, business strategy, and profitability in the Portuguese textile industry. The data were analyzed in different relationships using a structural equation model (SEM). The findings of the research emphasized the relevance of the choice of the business strategy as a partial mediator between the organizational capabilities and the profitability, a point that is necessary in comprehending organizational success and how resources and capabilities contribute to the process.

Zehir \& Zafer [29] investigated the effect of organizational capabilities on business performance. Data were collected from 456 owners and senior managers of 121 firms. The hypotheses were tested using regression analysis. The result revealed that increasing in the level on organizational capabilities has positive effect on business performance. Akaegbu \& Usoro [30] thoroughly researched the capability and strategy in firms. It embraces the process of documentation of important literature, making the research process more compelling and descriptive. The study revealed that there are nine procedures outlined in the strategy formulation process; the five essential capabilities and three levels of strategy were also noted. Emphasis was placed on the need for organizational capability, as well as its location and implementation of the plan.

Waribugo \& Onuoha [31] examined the association between organizational learning capability and growth of auto parts manufacturing firms in Nnewi, and to ascertain the moderating role of perceived organizational support. The study revealed that access to risk taking does not result in greater growth; interaction with the environment serves as triggers for growth. The research has also shown that perceived organizational support moderates the relationship between organizational learning capability and growth.

\section{METHODS}

This study made use of descriptive research design. The study population was drawn from the selected SMEs in Anambra State. The study conducted a census of all the 152 business owner/managers of the selected SMEs from the target population. Complete enumeration was adopted and so there was no need for sampling as all the selected SMEs were used. Primary data was used and was collected using questionnaires. The questionnaire was validated using face and content validity. Reliability analysis run with Cronbach Alpha indicates high internal consistency. Quantitative data analysis conducted using SPSS. Quantitative data was analyzed using correlation analysis.

\section{Statistical Results And Discussion}

\section{A. Hypothesis One}

Research and development capability has a significant positive relationship on firm's growth of selected SMEs in Anambra State Nigeria.

TABLE I: CORRELATION ANALYSIS FOR RESEARCH \& DEVELOPMENT CAPABILITY AND FIRM'S GROWTH

\begin{tabular}{|c|c|c|c|}
\hline \multicolumn{4}{|c|}{ Correlations } \\
\hline & & REDECA & FIRGOW \\
\hline \multirow{3}{*}{ REDECA } & $\begin{array}{c}\text { Pearson } \\
\text { Correlation }\end{array}$ & 1 & $0.174^{* *}$ \\
\hline & Sig. (2-tailed) & & 0.000 \\
\hline & $\mathrm{N}$ & 152 & 152 \\
\hline \multirow{3}{*}{ FIRGOW } & $\begin{array}{c}\text { Pearson } \\
\text { Correlation }\end{array}$ & $0.174^{* *}$ & 1 \\
\hline & Sig. (2-tailed) & 0.000 & \\
\hline & $\mathrm{N}$ & 152 & 152 \\
\hline
\end{tabular}

REDECA $=$ Research \& Development Capability.

FIRGOW $=$ Firm Growth .

The correlation analysis carried out between research \& development capability and firm's growth of selected SMEs in Anambra State Nigeria. The correlation coefficient obtained was 0.174 which shows a low positive relationship.

TABLE II: SIGNIFICANCE TEST FOR HYPOTHESIS ONE

\begin{tabular}{ccccc}
\hline \multicolumn{5}{c}{ TABLE II: SIGNIFICANCE TEST FOR HYPOTHESIS ONE } \\
\hline 152 & Cal. $\mathrm{R}$ & $\mathrm{df}$ & Crit. r. & Remark \\
\hline & 0.174 & 150 & 0.208 & Not Significant \\
\hline
\end{tabular}

Table II indicates the test of significance for hypothesis one. It revealed that at 0.01 level of significance and at 150 degrees of freedom, that the critical $r$ is 0.208 . The calculated $\mathrm{r}(0.174)$ is less than the critical $\mathrm{r}$ (cal. $\mathrm{r} 0.174>$ crit. $\mathrm{r} 0.208$ ) therefore, the result did not support the hypothesis.

This result might be these reasons. First, it may occur that some SMEs have inadequate research and development expenses compare to their rivalries, so that such research and development costs may not lead to the expected innovation, which consequently does not improve the firm's market growth. Also, research and development capability is likely to be more imitable and mobile; thus based on the absence of fully functional markets for innovation, larger firms may be better at spreading the fixed costs of research and development over huge sales. Larger firms may also be able to exploit economies of scale in the conduct of the research and development activity itself [32].

\section{B. Hypothesis Two}

Human resource capability has a significant positive relationship on firm's growth of selected SMEs in Anambra State Nigeria.

The correlation analysis carried out between human resource capability and firm's growth of selected SMEs in Anambra State Nigeria. The correlation coefficient obtained was 0.628 which shows a positive relationship.

TABLE III: CORRELATION ANALYSIS FOR HUMAN RESOURCE CAPABILITY AND FIRM'S GROWTH

\begin{tabular}{cccc}
\hline \multicolumn{4}{c}{ Correlations } \\
\hline \multirow{4}{*}{ HURECA } & HURECA & FIRGOW \\
\hline & Pearson & 1 & $0.628^{* * *}$ \\
& $\begin{array}{c}\text { Correlation } \\
\text { Sig. (2-tailed) } \\
\text { N }\end{array}$ & 152 & 0.000 \\
& & & 152 \\
\hline
\end{tabular}




\begin{tabular}{cccc}
\hline & Pearson & $0.628^{* *}$ & 1 \\
FIRGOW & Correlation & & \\
& Sig. (2-tailed) & 0.000 & 152 \\
$\mathrm{~N}$ & 152 & 152 \\
**. Correlation is significant at the 0.01 level (2-tailed).
\end{tabular}

REDECA = Human resource capability.

FIRGOW $=$ Firm Growth

TABLE IV: SIGNIFICANCE TEST FOR HYPOTHESIS TwO

\begin{tabular}{ccccc}
\hline $\mathrm{N}$ & Cal. R & df & Crit. r. & Remark \\
\hline 152 & 0.628 & 150 & 0.208 & Significant \\
\hline
\end{tabular}

Table IV indicates the test of significance for hypothesis one. It revealed that at 0.01 level of significance and at 150 degrees of freedom, that the critical $r$ is 0.208 . The calculated $\mathrm{r}(0.628)$ is greater than the critical $\mathrm{r}$ (cal. $\mathrm{r} 0.628>$ crit. $\mathrm{r}$ 0.208 ) therefore, the result supported the hypothesis.

This result lend support to Goold \& Quinn [33] findings, that human resources are principal mechanism by which managers integrate the behaviour of individuals to align with the interests of the firm. Thus, human resources management has great effect on firm's growth. Ulrich \& Lake [34] posit that firm's human resources may be its most important and sustainable assets.

\section{CONCLUSION AND RECOMMENDATIONS}

Based on the findings of this study, it was concluded that research and development capability have no significant positive relationship on firm's growth of selected SMEs in Anambra State Nigeria. The study also concluded that human resource capability has a significant positive relationship on firm's growth of selected SMEs in Anambra State Nigeria. Therefore, in order to adapt to changes in the dynamic environment and the changes in firms' strategies, SMEs need to build the capacity necessary to constantly change their identity or threats that could drive out the market or industry. Organizational capability is a critical success factor and part of a firm's competence, and its development is in line with the resource-based theory.

In view of this, there was an urgent need for firms to embrace strategies that would lead to growth. In order to enhance growth, managers of SMEs should increase the degree of firms' interaction with external environment through research and development and by establishing more linkages and deepening the flow of information and ideas among related firms, both locally and abroad. The study also suggested that firms should invest more in human resources than in their competitive environment.

\section{REFERENCE}

[1] Vorhies, D.W., Michael H., \& Rao. C.P. The Capabilities and Performance Advantages of Market-Driven Firms. European Journal of Marketing, 2019, 33 (11/12), 1171-1202.

[2] Tracey, M., Lim. F.S. \& Vonderembse, M.A. The Impact of SupplyChain Management Capabilities on Business Performance. Supply Chain Management: An International Journal, 2005, 10/3, 179-191.

[3] Moore, M., \& Fairhurst, A. Marketing capabilities and firm performance in fashion retailing. Journal of Fashion Marketing and Management, 2003, 7 (4), 386-397.

[4] Maier, A., Moultrie, J., \& Clarkson, P.J. Assessing Organizational Capabilities: Reviewing and Guiding the Development of Maturity Grids. IEEE. Transactions on Engineering Management, 2012, 59(1), 138-159. https://doi.org/10.1109/TEM.2010.2077289.
[5] Vorhies, D.W. \& Morgan, N.A. Benchmarking marketing capabilities for sustainable competitive advantage. Journal of Marketing; 2005, 69(1): 80-94.

[6] Teece, D.J. Towards a capability theory of (innovating) firms: implications for management and policy, Cambridge Journal of Economics, 2017, 41(3), 1, 693-720, doi.org/10.1093/cje/bew063.

[7] Weerawardena J. Exploring the role of market learning capability in competitive strategy. European Journal of Marketing, 2003, 37(3/4) 407-429.

[8] López, S.V. Competitive advantage and strategy formulation: the key role of dynamic capabilities, Management Decision, 2005, 43(5), 661669.

[9] Benedetto, C.A., \& Song, M. The relationship between strategic type and firm capabilities in Chinese firms. International Marketing Review, 2003, 20(5), 514-533.

[10] Luo, J. Fan, M. \& Zhang, H. "Information technology and organizational capabilities: A longitudinal study of the apparel industry", Decision Support System, 2012, 53(1), 186-194.

[11] Smallwood, N \& Ulrich, D., Capitalizing on capabilities. Harvard Business Review, 2004, 40, (3): 119-127.

[12] Eisenhardt, K.M., \& Martin, J.A. Dynamic capabilities: What are they? Strategic Management Journal, 2000, 21((10-11)), 1105-1121.

[13] Gill L., \& Delahaye B.L. Building organizational capability: your future, your business. 18th Annual Conference of the Australian and New Zealand Academy of Management, Dunedin, New Zealand, 2004

[14] Kelchner, L., The importance of organizational capability. 2016. Retrieved on $12^{\text {th }}$ June 2021 from www.smallbusiness.chrom.com.

[15] Day, G.S. The capabilities of market-driven organizations. The Journal of Marketing; 1994, 37-52.

[16] Knight, G.A., \& Cavusgil, S.T. Innovation, organizational capabilities, and the born-global firm. Journal of International Business Studies, 2004, 35(4): 124-141.

[17] Sharma, S., \& Vredenburg, H. Proactive corporate environmental strategy and the development of competitively valuable organizational capabilities. Strategic Management Journal, 1998, 19(1), 729-753.

[18] Penrose, E.T. The Theory of the growth of the firm. Oxford: Oxford University Press, 2015

[19] Nelson, R.R. \& Winter, S.G. An Evolutionary Theory of Economic Change. Cambridge, M.A., Belknap Press of Harvard University Press, 2012.

[20] Flamholtz, E.G. Managing the Transition from an Entrepreneurship to a Professionally Managed Firm. San Francisco: Jossey-Bass, 2016.

[21] Zhou, H. \& Wit, G. Determinants and Dimensions of Firm Growth SSRN Electronic Journal, 2009. DOI: 10.2139/ssrn.1443897.

[22] Davidsson, P., Achtenhagen, L., Naldi, L. Research on Small Firm Growth: A Review. In European Institute of Small Business, 2015.

[23] Storey, D. New Perspectives on Human Resource Management. Routledge, London, 2014. https://doi.org/10.4324/9781315740560.

[24] Rosenfeld, S.A. Industry Clusters: Business Choice, Policy Outcome, or Branding Strategy? Journal of New Business Ideas and Trends, 2005, 3(2), 4-13.

[25] Johnson, G., Sholes, K \& Whittington, R. Exploring corporate strategy, 8th Edition. London: Prentice Hall, 2008.

[26] Barney, J.B. Firm resources and sustained competitive advantage. $\begin{array}{llll}\text { Journal of Management, 1991, 17(1), 99-121. } & \end{array}$ doi:10.1177/014920639101700108

[27] Asikhia, O.U., Makinde, O.G., \& Olowoporoku, A.A. The Role of Organizational Capabilities in the Competitiveness of Hotels in Southwest Nigeria. Gph - International Journal of Business Management, 2021, 4(05).

[28] López-Cabarcos, M.Á., Göttling-Oliveira-Monteiro, S., \& VázquezRodríguez, P. Organizational capabilities and profitability: The mediating role of business strategy. Sage Open, 2015, 5(4), 2158244015616852.

[29] Zehir, C. \& Zafer, A.A. The Harmonized Effects of Generic Strategies and Business Capabilities on Business Performance. Journal of Business, Economics and Management, 2010, 4: 689-711.

[30] Akaegbu, J.B. \& Usoro, A.A. The Place of Organizational Capabilities in Strategy Formulation and Implementation: An Exploratory Analysis. Global Journal of Social Sciences, 2017, 16: 39-48. DOI: https://dx.doi.org/10.4314/gjss.v16i1.5.

[31] Waribugo, S. \& Onuoha, B.C. Organizational Learning Capability, Perceived Organizational Support and Growth of Auto Parts Manufacturing Firms in Nigeria. European Journal of Business and Management, 2016, 8(17).

[32] Feng, Y.Y. Pan, W.H, Huang, Y.C. \& Chen, Y.K. The effect of Firm's Resources and Capabilities on its Performance of IC Design Industry in Taiwan. Information Technology Journal, 2009, 8(5), 688-697.

[33] Goold, M. \& Quinn, J.J. The Paradox of Strategic Controls. Strategic Management Journal, 1990, 11, 43-57. 
https://doi.org/10.1002/smj.4250110104

[34] Ulrich, D. \& Lake, D. Organizational Capability: Creating Competitive

Advantage, Academy of Management Executive, 1990, 5, 77-92. 